\title{
REGIME ALIMENTAR DE SCHIZODON INTERMEDIUS GARAVELLO \& BRITSKI DO RIO TIBAGI, PARANÁ, E SUA RELAÇÃO COM ALGUMAS CARACTERISTICAS MORFOLÓGICAS DO TRATO DIGESTIVO (OSTEICHTHYES, ANOSTOMIDAE)
}

\author{
Regina de Souza Yabe ${ }^{1}$ \\ Sirlei Terezinha Bennemann ${ }^{2}$
}

\begin{abstract}
DIET COMPOSTIION OF SCHIZODON INIERMEDIUS GaRAVELlo \& BRITSKI OF THE TIBAGI RIVER. PARANÁ ANI) ITS RELATION TO SOME MORPHOLOGICAL CHARACTERISTICS OF THE DIGESTIVE TKACT (OSIEICHTHYES, ANOSTOMIDAE). In order to analyse the diet of Schizolon intermedius Garavello \& Britski, 1990, captures were made every season during the period of April/1990 to February/1991, using gillnets of different mesh size at Sertanópolis, a region of Paraná State. An analysis of stomach fullness degree was made upon 76 individuals (including young ones). A sample of 20 adult specimens was chose to compare the morphology of the digestive tract with the diet found. It was concluded that $S$. intermedius is a grazer herbivore whose principal diet consists of leaves and stalks of two monocotyledonous plants: Poaceae and/or Cyperaceae. This species shows quantitative, but not qualitative feeding seasonal variations. It was verified that intestinal quotient of the species is $X=1.34$, the variation of gill rakers number is $18-23$ and of the pylorie caeca number is 15-25. These morphological characteristies found in this species are typical of herbivore fishes.

KEY WORDS. Pisces, Anostomidae, Schizodon intermedius, food, herbivore
\end{abstract}

Desde 1989, com a implantação do Consórcio Intermunicipal de Proteção à Bacia do Rio Tibagi (COPATI), tem sido desenvolvido estudos em diversas áreas de conhecimento, ao longo da bacia. O Projeto: "Aspectos da Fauna e Flora da Bacia do Rio Tibagi" desenvolvido pela Universidade Estadual de Londrina é parte integrante do plano global deste Consórcio e possui, concluídos e em desenvolvimento, vários trabalhos.

Com relação à ictiofauna, foi efetuado o primeiro levantamento em trechos de cinco localidades ao longo da bacia (BENNEMANN et al. 1994) e alguns estudos sobre a biologia de espécies coletadas neste levantamento GuIDETTI (1992) e ARAÚJo et al. (1993).

Da mesma forma, as amostras da espécie de nosso estudo, Schizodon intermedius, são provenientes de uma das localidades estudadas em tal levantamento.

1) Rua Prof. João Cândido 1404 ạp. 502, 86010-001 Londrina, Paraná, Brasil.

2) Departamento de Biologia Animal e Vegetal, Centro de Ciências Biológicas, Universidade Estadual de Londrina, Caixa Postal 6001, 86051-970 Londrina, Paraná, Brasil. 
Esta espécie foi descrita recentemente por GARAVELLO \& BRITSKI (1990) e se encontra entre as escolhidas para estudos em cultivo, na Estação de Piscicultura da Universidade Estadual de Londrina.

Com o objetivo de caracterizar o regime alimentar de Schizodon intermedius, de acordo com a sazonalidade e relacionar o mesmo com a morfologia do trato digestivo, este trabalho é uma contribuição ao conhecimento da biologia das espécies de peixes do rio Tibagi e subsídio para possibilitar um manejo adequado, quanto aos recursos alimentares utilizados em cultivos.

\section{MATERIAL E MÉTODOS}

Os exemplares de Schizodon intermedius foram coletados no rio Tibagi, localidade Sertanópolis (Paraná), aproximadamente $23^{\circ} \mathrm{S} 51^{\circ} \mathrm{W}$, em cada uma das estações do ano, no período abril/1990 a fevereiro/1991. Neste local, o rio Tibagi apresenta grande influência da barragem do rio Paranapanema, formando baías onde há abundante vegetação aquática. As margens são desprovidas de mata ciliar, havendo poucas manchas remanescentes de vegetação. A terra é utilizada totalmente para agricultura.

Os peixes foram capturados através de redes de espera de diferentes tamanhos de malhas. Em campo, após a identificação, tomou-se os dados biométricos dos exemplares e mediante incisão na região abdominal, o trato digestivo de cada indivíduo foi retirado, pesado e observado o estádio de maturação gonadal.

O grau de repleção de cada estômago foi determinado conforme a escala utilizada por BENNEMANN (1985), porém modificada, considerando-se apenas os aspectos externos (Tab. I).

Os estômagos que continham alimento foram fixados em formol $4 \%$ e levados ao laboratório para a análise do conteúdo estomacal.

O grau médio de repleção $(\overline{\mathrm{GR}})$ sazonal foi calculado, empregando-se a expressão, segundo SANTOS (1981):

$$
G R=\frac{\sum i \cdot f a}{f a}
$$

onde: $\mathbf{i}=$ grau de repleção atribuído (pontos de acordo com a tabela I); fa = freqüência absoluta de exemplares com o grau "I".

Os itens alimentares do conteúdo estomacal foram separados em amostras sob microscópio estereoscópico.

Com o objetivo de identificar os alimentos de origem vegetal, foram coletados alguns exemplares da vegetação marginal e aquática, próximos dos locais onde foram armadas as redes. Após a identificação desses exemplares até a menor categoria taxonômica possível, fez-se diversas amostras com diferentes partes das plantas, fixadas em álcool $70 \%$. Através deste procedimento foi possível comparar as amostras de plantas encontradas no ambiente e no conteúdo estomacal.

A identificação das plantas coletadas realizou-se com base na seguinte literatura: BuRKART \& KLEIN (1979), LORENZI (1982), SEHNEM (1979) e SMITH et al. (1988). 
Tabela I. Descrição dos aspectos externos para estimativa do grau de repleção dos estômagos com os respectivos pontos atribuídos.

\begin{tabular}{|c|c|c|}
\hline Grau de repleção & Características externas & Pontos \\
\hline 0 - Vazio & $\begin{array}{l}\text { Estômago sem alimento presente. Parede das porções } \\
\text { cárdica e pilórica muito espessa. Diâmetro da porção } \\
\text { pilórica correspondente à espessura da parede que ao ser } \\
\text { palpada, sente-se muito consistente. }\end{array}$ & 0 \\
\hline 1 - Pouco (1/4 cheio) & $\begin{array}{l}\text { Alimento na porção cárdica em maior quantidade que o } \\
\text { grau anterior. }\end{array}$ & 1 \\
\hline 2 - Freqüente ( $1 / 2$ cheio) & $\begin{array}{l}\text { Alimento ocupando as duas porções, estando a maior } \\
\text { quantidade na região cárdica, cuja parede torna-se mais } \\
\text { delgada em metade da sua extensão. O diâmetro da } \\
\text { porção pilórica aumenta na região anterior. }\end{array}$ & r \\
\hline 3 - Cheio (3/4 cheio) & $\begin{array}{l}\text { Alimento ocupando toda a porção cárdica e metade da } \\
\text { pilórica. A parede da porção cárdica torna-se delgada em } \\
\text { toda a sua extensão. O diâmetro da porção pilórica } \\
\text { aumenta muito na metade anterior e em menor graus na } \\
\text { restante. }\end{array}$ & 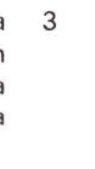 \\
\hline 4 - Distentido ( $4 / 4$ cheio) & $\begin{array}{l}\text { Alimento ocupando completamente o estômago. A } \\
\text { parede das duas porções torna-se tão delgada, que ao } \\
\text { ser manuseada facilmente se rompe. O diâmetro da } \\
\text { porção pilórica aumenta em toda a extensão. }\end{array}$ & 4 \\
\hline
\end{tabular}

Escala utilizada por BENNEMANN (1985), modificada.

As amostras contendo o item alimentar algas foram observadas sob microscópio de rotina Zeiss modelo Axioskop equipado com câmara clara, em lâminas temporárias. A identificação das algas realizou-se com base em PrESCOTT (1978) e STRELbe \& Krauter (1987).

A análise qualitativa foi realizada através do método de freqüência de ocorrência (WINDELL 1968) e a quantitativa pelo método de pontos (HYNES 1950), sendo os itens alimentares classificados nas seguintes categorias: raro, até $10 \%$ do alimento total ( 0,5 ponto); pouco, até $25 \%$ ( 1,0 ponto); freqüente, até $50 \%$ ( 2,0 pontos); comum, até 75\% (3,0 pontos) e muito comum, até 100\% (4,0 pontos).

Os resultados foram comparados entre as estações do ano.

Para obtenção do valor de cada item utilizou-se a seguinte expressão:

$$
\text { Valor de cada item }=\frac{\sum i . f a}{f a}
$$

onde: $\mathbf{i}=$ ponto atribuído; $\mathbf{f a}=$ freqüência absoluta de itens com "I" pontos (SANTOS 1981).

Como o método dos pontos estima os valores relativos dos itens alimentares, as algas não foram consideradas devido a dificuldade de se estimar o seu volume.

Para verificar a relação existente entre a atividade alimentar e o armaze- 
namento de gordura na cavidade abdominal de indivíduos adultos, nas diferentes estações do ano, calculou-se em 59 exemplares, os graus médios de repleção $(\overline{\mathrm{GR}})$ e gordura $(\overline{\mathrm{GG}})$.

A quantificação feita com o uso do $\overline{\mathrm{GG}}$, obedeceu ao mesmo critério utilizado no $\overline{\mathrm{GR}}$. Desta forma, a gordura visceral foi classificada em quatro categorias, conforme tabela II.

Em relação à morfologia do trato digestivo, foram selecionados 20 exemplares adultos para determinar a variação do número de rastros branquiais e cecos pilóricos e do quociente intestinal, que consiste na razão entre o comprimento do intestino e do comprimento total do peixe.

A contagem dos rastros branquiais foi feita somente na face externa do primeiro arco branquial esquerdo. Foram contados os rastros das porções superior, inferior e do ângulo, inclusive os rudimentares.

O intestino foi medido sobre régua milimetrada, da sua porção inicial até o nível da abertura anal, desfazendo-se as dobras sem esticá-lo.

Tabela II. Deserição das características consideradas para estimativa do grau de gordura visceral com os respectivos pontos atribuídos.

\begin{tabular}{clc}
\hline Grau de Gordura & \multicolumn{1}{c}{ Características } & Pontos \\
\hline Ausente & Paredes do tubo digestivo totalmente sem gordura. & 0 \\
Pouco & $\begin{array}{l}\text { Gordura envolvendo de maneira não uniforme as paredes do } \\
\text { tubo digestivo. }\end{array}$ & 1 \\
Freqüente & $\begin{array}{l}\text { Gordura envolvendo as peredes do tubo digestivo de maneira } \\
\text { uniforme; ausente somente em estreitas faixas longitudinais. }\end{array}$ & 2 \\
Repleto & $\begin{array}{l}\text { Gordura envolvendo totalmente as paredes do tubo } \\
\text { digestivo. }\end{array}$ & 3 \\
\hline
\end{tabular}

\section{RESULTADOS}

Foram analisados 76 indivíduos jovens e adultos $(12,4-29,0 \mathrm{~cm})$ de Schizodon intermedius e destes, 32 exemplares $(42,10 \%)$ apresentaram estômagos vazios. A estação correspondente à maior porcentagem de estômagos com grau de repleção zero foi o inverno, pois $60 \%$ destes não continham alimento. Já no verão, houve a maior ocorrência de estômagos com grau de repleção elevado (Fig. 1). Os valores do $\overline{\mathrm{GR}}$ máximo e mínimo ocorreram, respectivamente, no verão e no inverno (Fig. 2).

Correlacionando o $\overline{\mathrm{GR}}$ com o $\overline{\mathrm{GG}}$, em 59 indivíduos adultos de $S$. intermedius, observou-se que a maior quantidade de gordura armazenada na cavidade abdominal $(\overline{\mathrm{GG}})$ se deu no inverno, justamente quando houve menor $\overline{\mathrm{GR}}$. $\mathrm{O}$ contrário ocorreu durante o verão quando foi verificado o menor $\overline{\mathrm{GG}}$ e o maior $\overline{\mathrm{GR}}$ (Fig. 3).

Ainda observou-se que, na primavera, um maior número destes exemplares 


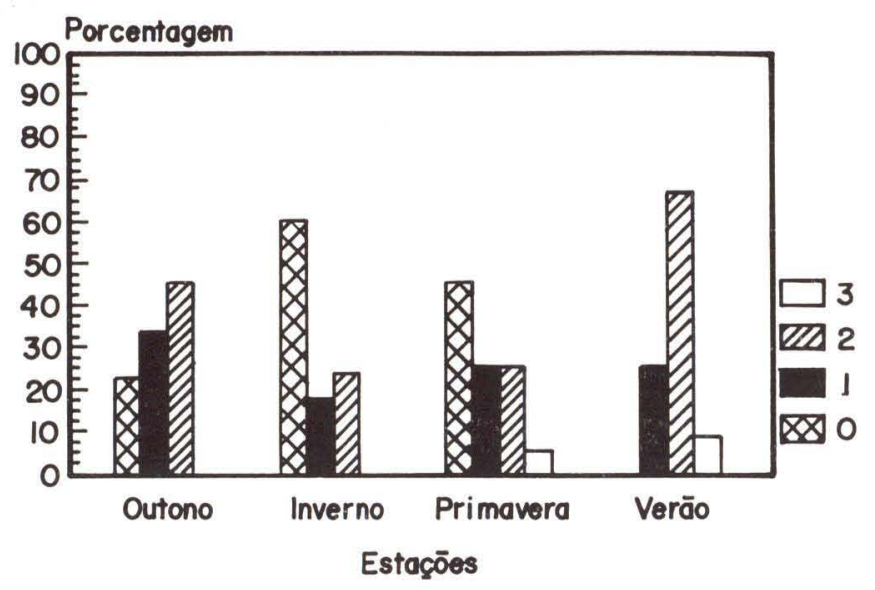

Fig. 1. Freqüências relativas dos graus de repleção de 76 exemplares de $S$. intermedius, coletados nas quatro estações do ano no Rio Tibagi, Sertanópolis (Paraná), no período abril 1990 a fevereiro 1991.

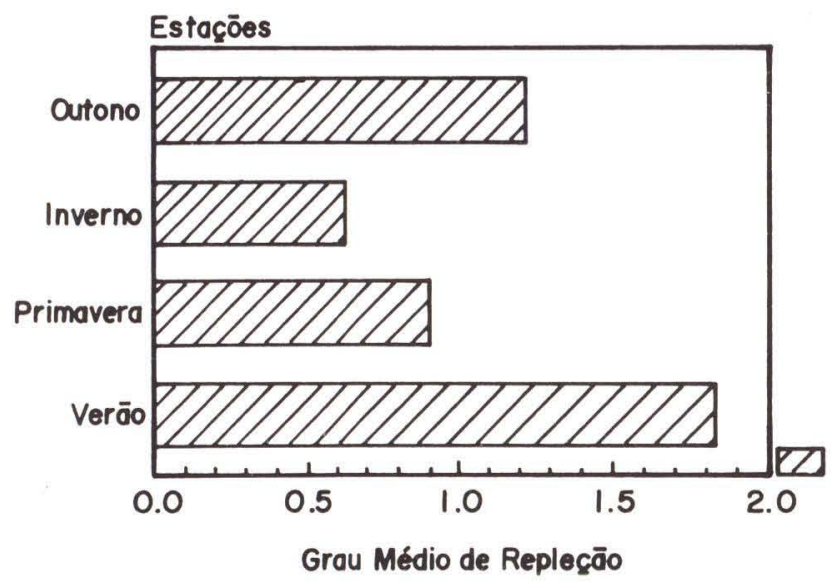

Fig. 2. Grau médio de repleção $(\overline{\mathrm{GR}})$ de 76 exemplares $S$. intermedius, coletados nas quatro estações do ano no Rio Tibagi, Sertanópolis (Paraná), no período abril 1990 a fevereiro 1991.

se encontravam em estágios mais avançados de maturação gonadal, porém durante este período, a atividade alimentar esteve reduzida $(\overline{\mathrm{GR}}=0,65)$. Entretanto, na estação seguinte (verão), o processo se inverteu, pois houve a maior atividade alimentar durante $\mathrm{o}$ ano $(\overline{\mathrm{GR}}=1,83)$ e uma diminuição no número de exemplares em estádios mais avançados de maturação gonadal.

Os resultados da análise qualitativa dos conteúdos estomacais (freqüência de ocorrência) para $S$. intermedius, em relação às quatro estações do ano, podem 


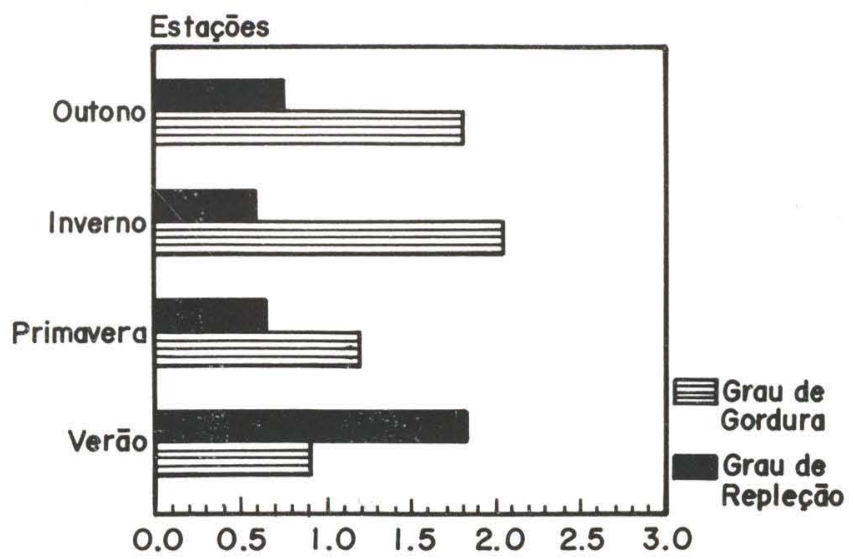

Fig. 3. Graus médios de repleção $(\overline{\mathrm{GR}})$ e gordura $(\overline{\mathrm{GG}})$ de 59 exemplares adultos de $S$. intermedius, coletadas nas quatro estações do ano no Rio Tibagi, Sertanópolis (Paraná), no período abril 1990 a fevereiro 1991 .

ser observados na fïgura 4. Através desta análise, identificou-se os seguintes itens alimentares:

1) Insetos: larvas e pupas de Diptera (Simulidae e Chironomidae), Trichoptera.

2) Vegetais vasculares: raízes de Salvinia auriculata Aublet e Eichhornia crassipes Marth Solms, raízes de Poaceae (gramíneas), folhas e caules de monocotiledôneas (Poaceae e/ou Cyperaceae), inflorescências e sementes não identificadas.

3) Microcrustáceos: Cladocera, Copepoda, Ostracoda.

4) Restos animais: material semi-digerido, basicamente larvas de insetos não identificados.

5) Sarcodina (Tecamebas): Difflugia Leclerc, Euglypha Dujardin.

6. Algas: foi possível identificar representantes das seguintes divisões: Chlorophyta, Chrysophyta (Bacillariophyceae), Cyanophyta, Euglenophyta e Pyrrophyta (Tab. III). Houve um predomínio de Chlorophyta e Chrysophyta. As demais divisões (Euglenophyta, Cyanophyta e Pyrrophyta) ocorreram com menor freqüência (Fig. 5).

Como pode ser observado na figura 4 , os itens alimentares algas e vegetais vasculares obtiveram, em todas as estações, $100 \%$ de freqüência de ocorrência, exceto no outono, quando houve uma diminuição na freqüência do item vegetais vasculares em relação às algas. Os demais itens alimentares não alcançaram freqüência de ocorrência maior que $50 \%$ em nenhuma das estações do ano. Dentre estes alimentos, o item insetos obteve a maior freqüência média de ocorrência $(31,25 \%)$, sendo no verão maior que $40 \%$.

$\mathrm{Na}$ análise quantitativa dos itens alimentares constituintes da alimentação de $S$. intermedius, o item vegetais vasculares alcançou a maior proporção em todas 


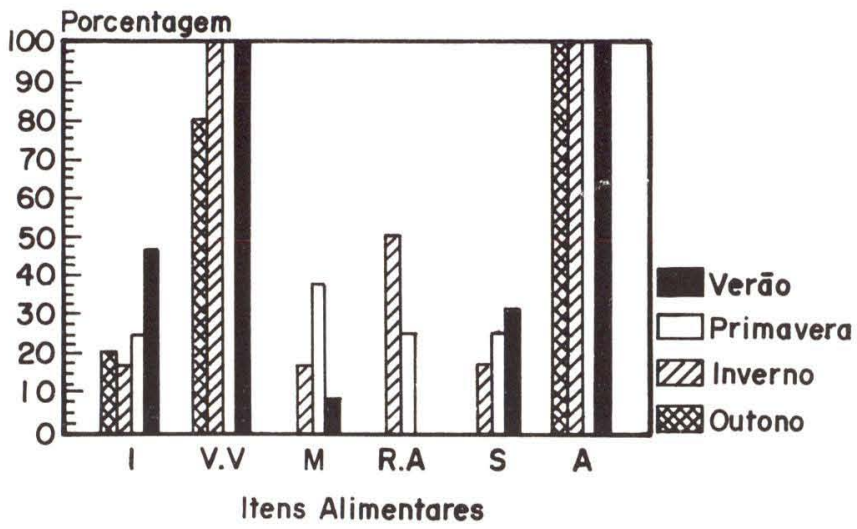

Fig. 4. Composição dos itens alimentares, calculados pelo método de freqüència de ocorrência em 32 exemplares de $S$. intcrmeditus, coletados nas quatro estações do ano no Rio Tibagi. Sertanópolis (Paraná), no período abril 1990 a fevereiro 1991. I.=Insetos; V.V.=Vegetais Vasculares: M.= Microcrustáceos; R.A.=Restos Animais; $\mathbf{S} .=$ Sareodina (Tecamebas); $\mathbf{A} .=$ Algas .

Tabela III. Gêneros e espécies de algas encontradas nos conteúdos estomacais de 32 exemplares de Schizodon intermedius.

Algas encontradas

Divisão Chlorophyta

Actinotaenium wollei (West \& West)

Teiling ex.: Ruzicka \& Pouzar

Closterium spp.

Coelastrum sp.

Cosmarium sp.

Desmidium sp.

Dimorphococcus lunatus A. Braum

Euastrum spp.

Gonathozigon sp.

Hyalotheca sp.

Kirchneriella sp.

Micrasterias sp.

Oedogonium spp.

Onychonema sp.

Pandorina sp.

Pediastrum sp.

Pleurotaenium sp.

Scenedesmos spp.

Selenastrum $\mathrm{sp}$.

Sphaerozosma aubertianum W. West

Spirogyra sp.

Skponddylosium spp.

Staurastrum spp.

Staurodesmos spp.
Algas encontradas

Divisão Chrysophyta (Bacillariophyceae)

Aulacoseira spp.

Eunotia sp.

Gomphonema sp.

Melosira sp.

Melosira varians C.A. Agardh

Divisão Cyanophyta

Anabaena sp

Oscillatoria sp.

Divisão Euglenophyta

Leponcin/s sp.

Phacus sp.

Trachelomonas sp.

Trachelomonas armata (Ehrenberg) Stein

Divisão Phyrrophyta

Dinophyceae 


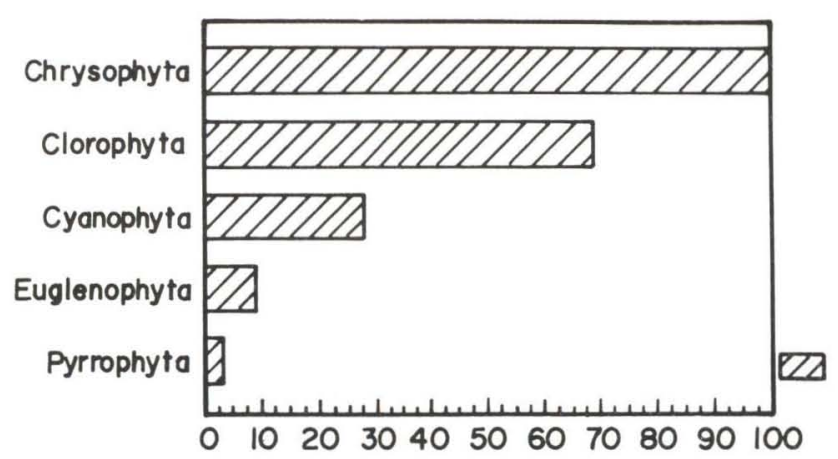

Fig. 5. Participação relativa das algas encontradas nos conteúdos estomacais de 32 exemplares de $S$. intermedius, coletados nas quatro estações do ano no Rio Tibagi, Sertanópolis (Paraná), no período abril 1990 a fevereiro 1991.

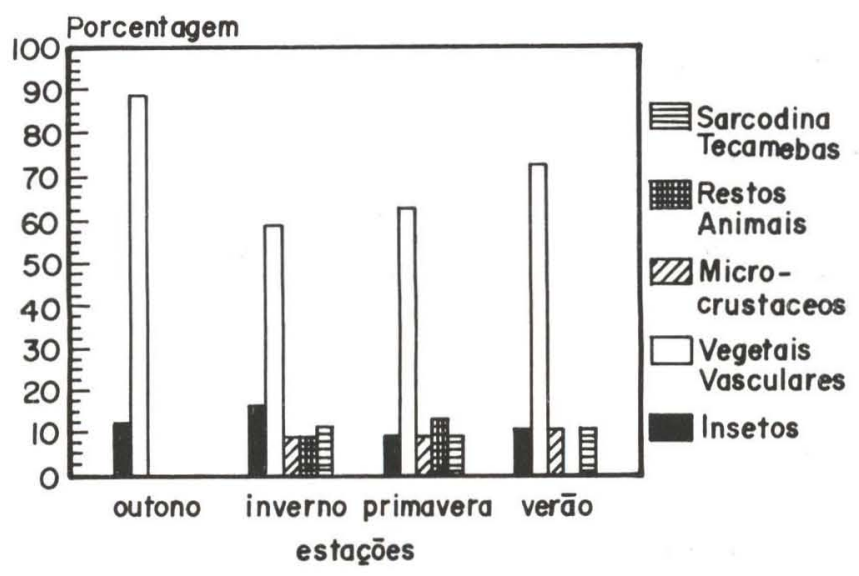

Fig. 6. Freqüência relativa dos intens alimentares, calculada, pelo métedo dos pontos em 32 exemplares de $S$. intermedius, coletados nas quatro estações do ano no Rio Tibagi, Sertanópolis (Paraná), no período abril 1990 a fevereiro 1991.

as estações, principalmente no outono, quando obteve $88,89 \%$ de freqüência relativa (Fig. 6).

$\mathrm{O}$ item que atingiu o segundo maior número de pontos foi insetos, durante todas as estações, exceto na primavera, quando houve um decréscimo em sua freqüência relativa em relação ao item restos animais.

A variação do número de rastros branquiais foi de 18-23 com média de 20,25 (DP =1.16) e dos cecos pilóricos 15-23 com média 17,65 ( DP =1,18).

O quociente intestinal médio de $S$. intermedius é de 1,34 sendo que dos 20 exemplares medidos, $35 \%$ apresentaram uma variação de 1,25 a 1,35 (Fig. 7). 


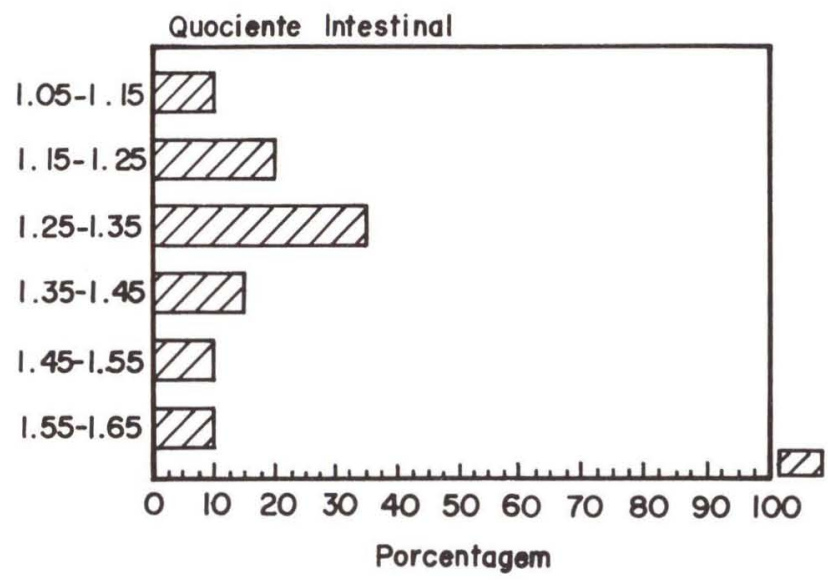

Fig. 7. Freqüencia relativa do quociente intestinal de 20 exemplares de S. intermedius, coletados nas quatro estações do ano no Rio Tibagi, Sertanópolis (Paraná), no período de abril 1990 a fevereiro 1991.

\section{DISCUSSÃO}

Mudanças sazonais ocorridas no habitat afetam os peixes, principalmente através de mudanças na quantidade e qualidade de alimento disponível LowE MCCONNELl (1987). No entanto, em S. intermedius ocorreu somente variação sazonal na quantidade de alimento, estando a maioria dos exemplares com estômagos vazios no inverno e alcançando valor máximo de repleção no verão. $\mathrm{O}$ item "vegetais vasculares", que se mostrou ser o principal alimento desta espécie, alcançou a maior proporção em todas as estações. Esta espécie foi herbívora durante todas as estações do ano, alimentando-se de algas e vegetais vasculares. Segundo KEENLEYSIDE (1979), espécies que ingerem pedaços de plantas acima do substrato são consideradas herbívoras-pastadoras. De acordo com o autor acima, S. intermedius pode ser assim considerada. SANTOS et al. (1984) também corroboram com esta classificação, mencionando que os Anostomidae apresentam uma tendência ao regime alimentar herbívoro como verificado para $S$. fasciatus Agassiz, 1829 (SANTOS 1981) e para S. nasutus Kner, 1859 e S. platae (Garman, 1890) (BENNEMANN 1985).

GOULDING \& CARVALHO (1982) consideram os peixes herbívoros altamente seletivos em relação às espécies e partes de plantas aquáticas ingeridas. Tal fato foi observado em $S$. intermedius, que mostrou nítida preferência por folhas e caules de monocotiledôneas (Poaceae e/ou Cyperaceae).

Correlacionando $\overline{\mathrm{GR}}$ com $\overline{\mathrm{GG}}$, verificou-se em $S$. intermedius, que durante as estações de reduzida atividade alimentar, havia maior armazenamento de gordura na cavidade abdominal. BENNEMANN (1985) constatou em $S$. nasutus e $S$. platae que os espécimes com estômagos vazios, durante o inverno, coincidiram ser os que apresentavam maiores reservas de gordura. Segundo WoOTTON (1990), 
a capacidade dos indivíduos não se alimentaram em certos períodos, depende da habilidade de acumular reservas, que podem ser mobilizadas quando a atividade alimentar cessa. No entanto, BENNEMANN (1985) concluiu que as variações sazonais na alimentação de $S$. nusutus e $S$. platıe mostram estar mais relacionadas com o período reprodutivo do que com a disponibilidade de alimento, pois na época de desova, houve uma diminuição na atividade alimentar, indicada pelo baixo $\overline{\mathrm{GR}}$. Nos indivíduos adultos de $S$. intermedius foi possível observar que na primavera, um maior número de exemplares atingiu estádios mais avançados de maturação gonadal e que durante este período, a atividade alimentar esteve reduzida. No verão, houve a inversão do processo, com a queda no número de espécimes em estádios de maturação gonadal avançada e aumento na atividade alimentar.

O número de rastros branquiais e cecos pilóricos verificados nas espécies do gênero Schizodon, em outros estudos, tem sido similares com os de $S$. intermedius, como pode ser visualizado na tabela IV.

Tabela IV. Variação total do número de rastros branquiais e cecos pilóricos nas espécies do gênero Schizolon.

\begin{tabular}{lcc}
\hline \multicolumn{1}{c}{ Espécie } & Rastros branquiais & Cecos pilóricos \\
\hline S. fasciatus Agassiz, 1829 & $21 \ldots 26$ & $17 \ldots-23$ \\
S. nasutus Kner, 1859 & $18 \ldots 24$ & $13 \ldots-18$ \\
S. plantae (Garman, 1890) & $18 \ldots 24$ & $13 \ldots-19$ \\
S. intermedius Garavello \& Britski, 1990 & $18 \ldots 23$ & $15 \ldots 20$ \\
\hline
\end{tabular}

* SANTOS (1980)

** BENnEMANn (1985)

HONDA (1974) relacionou o tamanho do intestino e o número de cecos pilóricos de Colossoma bidens com a necessidade de obter maior superfície de absorção e grande quantidade de enzimas digestivas, sendo que os peixes com tais características, geralmente alimentam-se de material que necessita de maior processamento para absorção dos elementos nutritivos. Entretanto, segundo Zavala (comunicação pessoal - Luis Alberto Zavala, Instituto de Pesca de São Paulo), as adaptações morfológicas do trato digestivo de peixes, em função dos diferentes hábitos alimentares, não podem ser comparadas isoladamente, pois é o conjunto de todas as estruturas relacionadas com o processo de digestão, que propicia à espécie a adaptação ao uso de determinado recurso alimentar.

Em $S$. intermedius, os resultados obtidos para o quociente intestinal, foram similares aos encontrados por SANTOS (1980) para $S$. fasciatus.

\section{CONCLUSÕES}

A maior e menor atividade alimentar ocorreram, respectivamente, no verão e inverno.

Há variações sazonais na quantidade de alimento, mas não na qualidade.

Em períodos de reduzida atividade alimentar, $S$. intermedius ou dispõe 
maior quantidade de gordura ou está relacionada com os estádios avançados de maturação gonadal.

O hábito alimentar de $S$. intermedius é do tipo herbívoro pastador, sendo sua dieta composta de folhas e caules de monocotiledôneas (Poaceae e/ou Cyperaceae), principalmente.

O quociente intestinal, o número de rastros branquiais e cecos pilóricos encontrados em $S$. intermedius são característicos de peixes de regime alimentar herbívoro.

AGRADECIMENTOS. Ao CNPq, pela Bolsa Iniciação Científica, ao COPATI (Consórcio Intermunicipal para Proteção da Bacia do Rio Tibagi), através do Convênio UEL/COPATI/KLABIN pelo auxílio financeiro, ao Dr. Júlio César Garavello da Universidade Federal de São Carlos, pelo valioso exame dos exemplares utilizados no estudo e identificação da espécie, ao Prof. Sandro Menezes da Silva pela identificação das plantas, e Ângela Teresa Silva e Souza e Claudia Bueno Martinez da Universidade Estadual de Londrina, pelo auxilio técnico e revisão.

\section{REFERÊNCIAS BIBLIOGRÁFICAS}

AraúJo, A.M.L.V.; C.M.N. Carmona \& A.K. Varoni. 1993. Aspectos da reprodução de fêmeas de Schizodon intermedius, Schizodon nasutus e Acestrorhynchus lacustris, do rio Tibagi na localidade de Sertanópolis, Paraná. Resumos do $10^{\circ}$ Encontro Brasileiro de Ictiologia, São Paulo, p. 134.

Bennemann, S.T. 1985. Aspectos da sistemática, alimentação e reprodução de Schizodon nasutus e Schizodon platae do Rio Ibicuí-Mirim, RS (Pisces Anostomidae). Dissertação de Mestrado, não publicada, Universidade Federal de Santa Maria, Santa Maria, 99p.

Bennemann, S.T.; A.T. Silva-Souza \& G.R.A. Rocha. (no prelo). Composición icitofaunistica em cinco localidades de la cuenca del Río Tibagi, Pr. Brasil. Interciencia, Caracas.

Burkart, A. \& R.M. Klein. 1979. Flora ilustrada catarinense: LeguminosasMimosideas. I Parte. Itajaí, P. Raulino Reitz, 304p.

Garavello, J.C. \& H.A. BRITSKI. 1990. Duas novas espécies do gênero Schizodon Agassiz da Bacia do Alto Paraná, Brasil, América do Sul (Ostariophysi, Anostomidae). Naturalia, São Paulo, 15: 153-170.

Goulding, M. \& M.L. CaRvalho. 1982. Life history and management of the Tambaqui (Colossoma macropomum, Characidae): an important amazonian food fish. Rev. bras. Zool. 1: 107-133.

GuidetTI, E. 1992. Regime alimentar de Geophagus brasiliensis (Perciformes, Cichlidae) do rio Tibagi (Telêmaco Borba) Pr. Londrina, Departamento de Biologia Animal e Vegetal, Universidade Estadual de Londrina, 57p. (Monografia).

HondA, E.M.S. 1974. Contribuição ao conhecimento da biologia de peixes do Amazonas. II. Alimentação do Tambaqui, Colossoma bidens (Spix). Acta Amazônica 4: 47-53. 
HYNES, H.B.N. 1950. The food of fresh water Sticklebacks (Gasterosteus aculeatus and Pygosteus pungitius), with a review of methods used in studies of the fishes. J. Anim. Ecol. 19: 36-58.

KeEnLEYSIDE, M.H.A. 1979. Diversity and adaptation in fish behavior. New York, Springer Verlag, 208p.

LOREnZI, H. 1982. Plantas daninhas do Brasil: terrestres, aquáticas, parasitas, tóxicas e medicinais. Nova Odessa, São Paulo, H. Lorenzi, 425p. Lowe MCCONNELL, R.H. 1987. Ecological studies in tropical fish communities. Cambridge, Cambridge University Press, 382p.

PrescotT, G.V. 1978. How to know the fresh water algae. Dubuque, Wm.C. Brown Company Publishers, $3^{a}$ ed., 293p.

SanTOS, G.M. 1980. Aspectos da sistemática e morfologia de Schizodon fasciatus Agassiz, 1829, Rhytiodus microlepis Kner, 1859 e Rhytiodus argenteofuscus Kner, 1859 (Osteichthyes, Characoidei, Anostomidae) do Lago Janauacá-Amazonas. Acta Amazônica 10 (3): 635-649.

- 1981. Estudos da alimentação e hábitos alimentares de Schizodon fasciatus Agassiz, 1829, Rhytiodus microlepis Kner 1859 e Rhytiodus argenteofuscus Kner, 1859, do Lago Janauacá-AM. (Osteichthyes, Characoidei, Anostomidae). Acta Amazônica 11: 267-283.

Santos, G.M.; M. Jegu \& B. Merona. 1984. Catálogo de peixes comerciais do Baixo Tocantins. Manaus, Eletronorte, CNPq, INPA, 83p.

SEHNEM, A.S.J. 1979. Flora ilustrada catarinense: Salviniaceae. I Parte. Itajaí, P. Raulino Reitz, 304p.

SMITH, L.B.; R.J. Downs \& R.M. KLEIN. 1988. Flora ilustrada catarinense: Euforbiaceae. I Parte. Itajaí, P. Raulino Reitz, 408p.

Strelbe, H. \& D. Krauter. 1987. Atlas de los microorganismos de agua dulce. Barcelona, Ediciones Omega S.A., 357p.

WINDELL, J.T. 1968. Food analysis and rate of digestion. In: W.E. RICKER (ed.). Methods for assessment of fish production in fresh waters. Oxford, Blackwell Scientific Publications, p. 197-203.

WoOtTon, J. 1990. Feeding. In: J. WoOTTON, J. (ed.) Ecology of Teleost fishes. London, Chapman and Hall, p.37-72.

Recebido em 13.VII.1994; aceito em 01.XII.1994. 